University of Wollongong

Research Online

Faculty of Science, Medicine and Health -

Papers: Part B

Faculty of Science, Medicine and Health

$1-1-2018$

\title{
Health screening for women with physical disability in Australian general practice: A survey
}

\author{
Elizabeth J. Halcomb \\ University of Wollongong, ehalcomb@uow.edu.au \\ Kathleen Peters \\ Western Sydney University \\ Elizabeth A. Smyth \\ University of Wollongong, esmyth@uow.edu.au
}

Follow this and additional works at: https://ro.uow.edu.au/smhpapers1

\section{Publication Details Citation}

Halcomb, E. J., Peters, K., \& Smyth, E. A. (2018). Health screening for women with physical disability in Australian general practice: A survey. Faculty of Science, Medicine and Health - Papers: Part B. Retrieved from https://ro.uow.edu.au/smhpapers1/140

Research Online is the open access institutional repository for the University of Wollongong. For further information contact the UOW Library: research-pubs@uow.edu.au 


\title{
Health screening for women with physical disability in Australian general practice: A survey
}

\begin{abstract}
Background: Early detection of gynaecological issues improves health outcomes and reduces mortality. Such early detection is best achieved via regular, proactive health screening. Like other disadvantaged groups, women with physical disability have much lower gynaecological screening rates than the general population.
\end{abstract}

Aim: The aim of this paper is to explore the current role of general practice nurses in women's health screening for individuals with physical disability. Methods: A national online survey of Australian general practice nurses was conducted.

Findings: One hundred and seventy-eight general practice nurses completed the survey. Sixty-one percent reported having experience in working with people with a physical disability. Around one third of participants reported having completed specific education about physical disability. Most general practices implemented strategies to facilitate physical access for those with disability. However, few general practices had a medical records system that enabled identification of physical disability. Thirtyseven participants reported providing women's health screening for 89 women with a physical disability in the 4 weeks prior to the survey. A range of strategies were used to support women during these screening procedures. These could be broadly classified into; a) providing practical assistance to facilitate screening, and b) modifying technique and positioning for comfort.

Conclusions: The limited experience with disability amongst an experienced nursing cohort, and the difficulty inherent in identifying those with a disability within recall and reminder systems, adds complexity to the provision of screening for women with a disability. Whilst participants articulated some innovative and creative strategies to assist women with a disability during health screening, enhanced awareness amongst nurses and proactive strategies would likely enhance service accessibility in this vulnerable group.

\section{Publication Details}

Halcomb, E. J., Peters, K. \& Smyth, E. (2019). Health screening for women with physical disability in Australian general practice: A survey. Collegian, 26 (2), 250-255. 
Title: Health screening for women with physical disability in Australian general practice: A survey

Running head: Screening for women with physical disability

Authors:

Elizabeth J. Halcomb RN BN(Hons) PhD FACN ${ }^{1}$

Professor of Primary Health Care

School of Nursing, University of Wollongong, Sydney Australia.

Kath Peters RN BN(Hons) PhD ${ }^{2}$

Associate Professor

School of Nursing \& Midwifery,

Western Sydney University, Sydney Australia.

Elizabeth Smyth BSc MPH ${ }^{1}$

Research Assistant

School of Nursing, University of Wollongong, Sydney Australia.

${ }^{1}$ School of Nursing, Faculty of Science, Medicine \& Health, University of Wollongong Northfields Ave Wollongong NSW 2522 Australia

${ }^{2}$ School of Nursing \& Midwifery, Western Sydney University. Locked Bag 1797 Penrith NSW 2751 Australia

Address for correspondence and reprints: Prof Elizabeth Halcomb. SN - Building 41, Northfields Ave Wollongong NSW 2522, Australia. E mail: ehalcomb@uow.edu.au 


\section{Abstract}

Background: Early detection of gynaecological issues improves health outcomes and reduces mortality. Such early detection is best achieved via regular, proactive health screening. Like other disadvantaged groups, women with physical disability have much lower gynaecological screening rates than the general population.

Aim: The aim of this paper is to explore the current role of general practice nurses in women's health screening for individuals with physical disability.

Methods: A national online survey of Australian general practice nurses was conducted.

Findings: One hundred and seventy-eight general practice nurses completed the survey. Sixty-one percent reported having experience in working with people with a physical disability. Around one third of participants had completed specific education about physical disability. Most general practices implemented strategies to facilitate physical access for those with disability. However, few general practices had a medical records system that enabled identification of physical disability. Thirty-seven participants reported providing women's health screening for 89 women with a physical disability in the 4 weeks prior to the survey. A range of strategies were used to support women during these screening procedures. These could be broadly classified into; a) providing practical assistance to facilitate screening, and b) modifying technique and positioning for comfort.

Conclusions: The limited experience with disability amongst an experienced nursing cohort, and the difficulty inherent in identifying those with a disability within recall and reminder systems, adds complexity to the provision of screening for women with a disability. Whilst participants articulated some innovative and creative strategies to assist women with a disability during health screening, enhanced awareness amongst nurses and proactive strategies would likely enhance service accessibility in this vulnerable group.

\section{Keywords:}

Practice Nurse, Nursing Workforce, Cancer Screening, Women, Disability, Primary Health Care 


\section{Problem or Issue}

Women with disability have much lower gynaecological health screening rates than the general population.

\section{What is Already Known}

Early detection of gynaecological health issues is best achieved via regular, proactive health screening. Women with a disability are less likely than able-bodied women to access screening or preventive care for gynaecological health issues.

\section{What this Paper Adds}

This paper highlights the difficulty in identifying people with physical disability in the general practice population within electronic medical records systems. It also identifies that most general practice nurses had not had any specific post-registration education to consolidate skills in working with individuals with a physical disability. 


\section{Introduction}

Gynaecological health screening, and early detection of gynaecological malignancy, significantly reduces morbidity and mortality (Australian Institute of Health and Welfare, 2008, 2011). Most deaths due to cervical and breast cancer are potentially avoidable with screening, early detection and timely evidence-based treatment (Australian Institute of Health and Welfare, 2007). Up to 85\% of women who develop cervical cancer have either never had a Pap smear or were inadequately screened (The Royal Australian College of General Practitioners, 2009). Participation rates in some national health screening programs are decreasing (Australian Institute of Health and Welfare, 2011). Despite having the most new cases and deaths from cervical cancer in Australia, NSW has one of the lowest participation rates in the National Cervical Screening Program (Australian Institute of Health and Welfare, 2011).

Women with a disability are less likely than able-bodied women to access gynaecological health screening (Chevarley, Thierry, Gill, Ryerson, \& Nosek, 2006; Smeltzer, 2006). In the USA, despite higher rates of health insurance and regular access to health services, women with disability are less likely to undergo breast and cervical screening than other women (Cooper \& Yoshida, 2007; Ramirez, Farmer, Grant, \& Papachristou, 2005). Women with physical disability also have a higher mortality rate due to some cancers, such as breast cancer, as they are often diagnosed at a more advanced stage than able-bodied women (McCarthy et al., 2006). American and Canadian research identifies several barriers to women with a disability participating in health screening, including: fear of or actual pain associated with procedures (Yankaskas et al., 2010), difficulties organising and attending appointments, including physical access and transportation (Angus et al., 2012; Morrison, George, \& Mosqueda, 2008; Mudrick, Breslin, Liang, \& Yee, 2012; Smeltzer, Sharts-Hopko, Ott, Zimmerman, \& Duffin, 2007), confronting assumptions about their bodies, gaining reliable health care and information (Angus et al., 2012); cost (Drew \& Short, 2010; Hagglund, Clark, Hilton, \& Hewett, 2005; Morrison et al., 2008; Yankaskas et al., 2010), and 
deficits in provider's knowledge of disability (Harrington, Hirsch, Hammond, Norton, \& Bockenek, 2009; Morrison et al., 2008), including lack of referral (Yankaskas et al., 2010).

There is a clear need to address health inequities, improve access to mainstream health services and employ strategies to enhance the uptake of evidence-based health screening for women with physical disability (Drew \& Short, 2010), including enhancing physical access and education for healthcare professionals (Morrison et al., 2008). However, few interventions to date have been translated to create sustainable services and systems.

\section{Literature Review}

There is a paucity of Australian research exploring the health screening practices of women with a physical disability (Peters, 2010; Peters, 2012). Much of the current evidence originates from the USA or Canada. The structural and funding differences between health systems internationally, particularly in primary care, create a need to investigate interventions within the Australian environment. This is particularly important since qualitative findings highlight the substantial barriers for women with physical disabilities accessing gynaecological health screening in Australia (Peters, 2010; Peters, 2012).

In the Australian health system, as the first point of contact for consumers, general practice is the broker and gatekeeper of health services (Halcomb, Davidson, Daly, Yallop, \& Tofler, 2005). As such general practices provide frontline medical services for acute care needs, as well as preventive health screening and management and ongoing care of those with chronic and complex disease. There has been a growing emphasis on the need to reform and strengthen Australian primary health care as the needs of the community are changing. Changes in health policy and funding have given rise to an expansion of the general practice nursing workforce (Halcomb, Salamonson, Davidson, Kaur, \& Young, 2014). General practice nurses are either baccalaureate prepared registered, or diploma prepared enrolled, nurses who are employed within a general practice. As registered or enrolled nurses, they have the knowledge and skills to undertake women's health screening within their scope of 
practice (Halcomb, Stephens, Bryce, Foley, \& Ashley, 2017; Nursing and Midwifery Board of Australia, 2016a, 2016b). General practice nurses have been demonstrated to provide care that is acceptable to consumers (Cheek et al., 2002; Halcomb, Caldwell, Davidson, \& Salamonson, 2011; Hegney, Price, Patterson, Martin-McDonald, \& Rees, 2004). Given that consumers often have ongoing relationships with a specific general practice, this setting provides a familiar environment and known clinicians (Halcomb, Davidson, Daly, Yallop, \& Tofler, 2004). In particular, general practice nurses have been identified to play an important role in connectivity and facilitation of service delivery (Phillips et al., 2008), particularly to diverse or disadvantaged groups such as women with a physical disability.

Australian general practice nurses are actively involved in gynaecological health screening (Byrnes, Crawford, Peers, \& McGoldrick, 2007; Halcomb, Davidson, Salamonson, \& Ollerton, 2008; Mills et al., 2012). The aim of this paper is to explore the current role of general practice nurses in gynaecological health screening for women with physical disability.

\section{Methods}

\section{Participants}

General practice nurses were informed about the study via email advertisements disseminated through Primary Health Care Organisations, the Australian Primary Health Care Nurses Association and via individual stakeholders and organisations. Additionally, snowballing techniques including social media (Twitter, Facebook and Linkedln) and professional websites were used to further disseminate study information. These advertisements included a link to the online survey. Email reminders were sent to all stakeholder groups on two occasions prior to the end of the survey period. It is difficult to estimate a sample size for the population of Australian general practice nurses given their dispersed employment by a large number of private general practices (Halcomb et al., 2014). 
However, this recruitment method is similar to that used in previous studies of this group (Ashley, Halcomb, Brown, \& Peters, 2018; Halcomb et al., 2014).

\section{Ethical considerations}

Approval was granted by the \#\#\#\#\# HREC and the HREC of the University of \#\#\#\#\# before the commencement of data collection (Approval No. HE13/521 \& H10477). Completion of the online survey was considered to indicate consent to participate.

\section{Design}

This cross-sectional survey used an investigator developed survey tool delivered online via SurveyMonkey ${ }^{\circledR}$ software. The survey aimed to capture information about general practice nurses' current role in women's health screening in general and, specifically, about how the nurse and their general practice facilitated and supported health screening of women with a physical disability. In this study we have allowed participants to respond based on their own understanding of physical disability as a nurse in clinical practice. This paper reports specifically on the data around screening of women with physical disability. The data about the broader general practice nurse role in women's health screening is reported elsewhere (AUTHORS OWN).

\section{Survey tool}

A descriptive survey tool was developed as there was limited previous survey work undertaken to collect information about the role of general practice nurses in the health screening of individuals with physical disability. This tool was developed following a review of the literature, discussions with experts in women's health, women with physical disability, and general practice nurses, the researcher's previous experience in women's health and their knowledge of survey design. To reduce the potential bias of a survey based solely on women with physical disability, items around women with physical disability were embedded within a broader survey which explored general practice nurses' involvement in women's health. 
The final tool consisted of 100 items; 16 demographic items; 59 items about women's health and 25 items about managing women's health screening for individuals with a disability. These items explored the scope of screening from recall and reminder to access and support before, during and after screening procedures. Items included a combination of dichotomous (yes/no) questions, Likert scales and open ended items.

The survey was pilot tested with a group of experienced researchers and general practice nurses to ensure face validity prior to dissemination. This testing resulted in some minor changes to the wording of some items to improve clarity and the online presentation of some items to enhance the ease of completion.

\section{Data analysis}

Data analyses were undertaken using the Statistical Package for the Social Sciences (SPSS) Version 21.0 (IBM Corp., 2013). Frequencies and percentages were used to summarise descriptive data. Pearson's chi-square $(\alpha=0.05)$ was used to determine relationships between survey items. Open ended items were analysed using thematic analysis.

\section{$\underline{\text { Results }}$}

One hundred and seventy-eight general practice nurses provided responses to the survey. As no participant completed all items a decision was taken not to exclude survey responses based on missing data. The number of responses for each item is shown in the various tables.

\section{Participant characteristics}

As shown in Table 1, most participants were female $(n=123 ; 99.2 \%)$ and aged over 40 years $(n=103 ; 81.1 \%)$. Despite the national survey distribution, the majority of participants were from NSW ( $n=81 ; 65.9 \%)$ and lived in regional areas $(n=82 ; 65.1 \%)$. Participants generally worked between $11-40$ hours per week. Almost $70 \%$ of participants had worked in either one or two general practices. Most participants were a qualified Pap smear provider ( $n=112 ; 89.6 \%)$ and many had been previously employed in sexual or women's health roles $(n=42 ; 33.0 \%)$. 
Table 1. Participant Demographics

\begin{tabular}{|c|c|c|}
\hline Demographic & $\mathbf{n}$ & $\%$ \\
\hline \multicolumn{3}{|l|}{ Gender (n=124) } \\
\hline Male & 1 & $0.8 \%$ \\
\hline Female & 123 & $99.2 \%$ \\
\hline \multicolumn{3}{|l|}{ Age $(n=127)$} \\
\hline $23-30$ & 7 & $5.5 \%$ \\
\hline $31-40$ & 17 & $13.4 \%$ \\
\hline $41-50$ & 47 & $37.0 \%$ \\
\hline $51-60$ & 45 & $35.4 \%$ \\
\hline $60+$ & 11 & $8.7 \%$ \\
\hline \multicolumn{3}{|l|}{ State/ Territory $(n=123)$} \\
\hline NSW & 81 & $65.9 \%$ \\
\hline VIC & 22 & $17.9 \%$ \\
\hline QLD & 7 & $5.7 \%$ \\
\hline WA & 5 & $4.1 \%$ \\
\hline SA & 3 & $2.4 \%$ \\
\hline TAS & 3 & $2.4 \%$ \\
\hline NT & 1 & $0.8 \%$ \\
\hline ACT & 1 & $0.8 \%$ \\
\hline \multicolumn{3}{|l|}{ Practice location $(n=126)$} \\
\hline Major city & 29 & $23.0 \%$ \\
\hline Regional (inner and outer) centres & 82 & $65.1 \%$ \\
\hline Remote/Very Remote & 15 & $11.9 \%$ \\
\hline \multicolumn{3}{|l|}{ Nursing classification $(n=127)$} \\
\hline Registered Nurse & 102 & $80.3 \%$ \\
\hline Enrolled Nurse & 4 & $3.1 \%$ \\
\hline $\begin{array}{l}\text { Other eg. Nurse Consultant ,Nurse Manager, Nurse } \\
\text { Specialist }\end{array}$ & 21 & $16.5 \%$ \\
\hline \multicolumn{3}{|l|}{ Highest educational qualification $(n=127)$} \\
\hline Hospital nursing certificate /Hospital advanced certificate & 30 & $23.6 \%$ \\
\hline Associate diploma & 8 & $6.3 \%$ \\
\hline Bachelor's degree & 41 & $32.3 \%$ \\
\hline Other eg. Graduate Certificate, Master's degree & 48 & $37.8 \%$ \\
\hline
\end{tabular}




\section{General practice nurse experience with disability}

Five (4.0\%) participants reported that they themselves had a physical disability. Just over half of participants $(n=77 ; 60.6 \%)$ reported having professional experience in working with people with physical disability. Fewer participants reported having either informal social contact with people with a disability $(n=17 ; 13.4 \%)$ or no experience with people with a disability $(n=21$; 16.5\%). A small number of participants reported having a family member / friend with a disability $(n=12 ; 9.4 \%)$.

\section{General practice nurses' experience with disability education / training}

Successful completion of an accredited pre-registration nursing course implies that Registered and Enrolled nurses are able to safely and effectively work with individuals with disability. In our study, approximately one third of participants $(n=43 ; 33.9 \%)$ reported that they had undergone additional training or education around working with people with a physical disability. This was mostly provided through short courses or workshops ( $n=30 ; 73.2 \%)$.

\section{Practice accessibility}

Strategies implemented by participants' general practices to facilitate access for those with a physical disability included ramps at entry points $(n=108 ; 85.0 \%)$, wide doorways $(n=106$; 83.5\%), easy access toilets ( $n=99 ; 78.0 \%)$ and consultation rooms $(n=94 ; 74.1 \%)$ and disabled parking $(n=93 ; 73.2 \%)$. Just over half of participants identified that their general practice provided assistance with booking transport $(n=71 ; 55.9 \%)$ for individuals with disability.

\section{Medical records}

Most participants reported using a reminder / recall system in their practice for women's health screening $(n=128 ; 95.5 \%)$. However, relatively few participants identified that this system had provision for identifying individualised physical $(n=48 ; 37.5 \%)$, mental health $(n=30 ; 23.4 \%)$ or language and communication needs $(n=26 ; 20.3 \%)$.

Only one third of participants $(n=41 ; 33.1 \%)$ worked in general practices with a medical records system that enabled the ready identification of women with physical disability. 
Approximately $36 \%(n=44)$ of general practice nurses worked in general practices that lacked this capacity, while approximately $32 \%(n=39)$ were unsure whether their medical records system could identify physical disability.

Information about a woman's physical disability status was usually recorded in the 'medical history', 'past history' or 'other' sections of their medical record. The recording of disability information however, was sometimes a function of the doctor's discretion. "Depending on the disability and at the GP's discretion, it will sometimes be noted in the patient details (PN)." Without a field to code in practice software, participants noted that the information could be listed in "the 'warnings' section, history or progress notes". This inconsistent recording created challenges in locating the information during bulk recalls of consumers to the practice. A few general practice nurses indicated they were aware of a woman's disability status as a result of prior contact. "As (the) practice is small, we know everybody who attends and what their limitations might be." However, others relied on "being able to see their disability".

\section{Disability-friendly strategies}

When asked to indicate from a list which strategies they used to support screening of women with a disability, approximately two in three participants provided physical types of assistance (Table 2). Relatively few participants reported providing strategies for those with cognition or reading issues, or home visits. The open-ended 'other' responses can be seen at the bottom of the table. 
Table 2: Strategies and Facilities to assist women with a disability

\begin{tabular}{|c|c|c|}
\hline Strategies/Facilities & $\mathbf{N}$ & $\%$ \\
\hline Adjustable examination table to assist patients in positioning & 91 & $71.7 \%$ \\
\hline Assistance in getting on the examination table & 86 & $67.7 \%$ \\
\hline Assistance with dressing/undressing & 82 & $64.6 \%$ \\
\hline Longer appointment times & 81 & $63.8 \%$ \\
\hline Nurse chaperone for appointments & 53 & $41.7 \%$ \\
\hline Home visits for routine care & 48 & $37.8 \%$ \\
\hline Someone to read and speak information to the patient & 44 & $34.6 \%$ \\
\hline Visual aids to assist in providing information & 23 & $18.1 \%$ \\
\hline Lifting device to position patient on examination table & 4 & $3.1 \%$ \\
\hline $\begin{array}{l}\text { Other } \\
\text { 1. electric exam table in some settings for community he } \\
\text { 2. Interpreter service } \\
\text { 3. Lift for access to Level B } \\
\text { 4. Red Cross transport available, Guide dogs allowed } \\
\text { 5. Some GP provide home visits }\end{array}$ & $\operatorname{tgp}$ & \\
\hline
\end{tabular}

\section{Health screening of women with a physical disability}

Thirty-seven participants (20.8\%) reported providing women's health screening for 89 women with physical disability in the 4 weeks prior to the survey. Of these participants most $(n=19$; $51.4 \%$ ) cited one occasion of screening with a woman with physical disability, with $24.3 \%$ $(n=9)$ reporting being involved in the screening of two women. However, one general practice nurse reported 10 occasions of service, and another general practice nurse reported 12 occasions of service, for women with physical disability during the preceding four weeks.

The participants who provided screening for women with a disability were not significantly different to those participants who did not provide screening, in terms of age $(p=0.40)$, highest education $(p=0.72)$, practice location $(p=0.09)$, hours employed $(p=0.61)$ or nursing classification $(p=0.70)$. 
Participants with additional training/education around disability were statistically significantly more likely to report not undertaking screening of people with a disability $(p=0.04)$. Conversely, those participants who reported experience with disability were significantly more likely to have provided health screening for women with a physical disability $(p=0.04)$.

Participants who provided screening for women with a disability were asked an open-ended question about how they modified their practice to accommodate the additional needs of these women. Of the 89 women with a disability who underwent health screening, 77 (86.5\%) needed additional physical and psycho-social assistance to facilitate the screening process. This was provided by the attending general practice nurse, as well as other staff, and patient carers and relatives when necessary. These needs were classified into the themes of a) providing practical assistance to facilitate screening and b) modifying technique and positioning for comfort.

\section{a) Providing practical assistance to facilitate screening}

Participants reported providing assistance related to appointment scheduling to suit client and longer time allowance to manage physical limitations and further time to explain and obtain consent. The participants also provided emotional support using reassurance, and spent time establishing rapport with women who had physical disabilities. Further, communication difficulties for hearing impaired women were reportedly managed by communication via their carer(s) or using the services of an interpreter.

Practical assistance was also provided to women with disability to assist in the screening process. This included helping with activities such as: help(ing) (patient) dress/ undress; support(ing) ambulating; removing shoes; and assistance on and off scales and examination couch. Further strategies used to assist women with disability included enlisting the help of family members or friends to assist (the client) onto (the) bed and one participant reported: "The patient(')s husband administered (a) mild sedative at a designated time before the appointment and helped with positioning and reassurance during the procedure". 
Electric beds, gynaecological beds and types that could be lowered for easy transfers, were used in some cases because they facilitated the delivery of the screening procedure. Electric beds were also used to adjust for comfort and position in cases where women were unable to support and position themselves. Some patients also used footstools; or a step stool to climb onto assessment table; and general practice nurses provided some women with a higher seat to avoid difficulty getting in and out of lower chairs and a high /low bed arm support.

\section{b) Modifying technique and positioning for comfort}

In order to promote comfort and facilitate the screening process, participants were creative in how they positioned women with disability. Positioning strategies used by participants involved using pillows and the assistance of other general practice nurses to ensure adequate support was provided for the screening to be completed. For example, they reported; Managing a Pap Smear in the left lateral position with another nurse assisting and Attend(ing) Pap Smear on side -use pillows for positioning. Additional pillows were used:... under hips for support for chronic back pain sufferers; (as) support for painful hips; under the pelvis; as back ... support . Another patient got extra pillows as she wasn't able to lie flat.

Participants described how they were able to modify their technique of obtaining a pap smear, demonstrating patient-centred care by taking a solution focussed, rather than problem focussed, approach to screening.

"Woman with paralysis found it easier to move from chair to floor for Pap (smear) rather than from chair to bed-put linen onto floor and accommodated to what she felt comfortable with."

"I've modified my technique to accommodate women who can't lay on their back or difficult to position to enable Pap Smear" 
"Altering the way I insert the speculum slightly to accommodate reduced hip movement."

\section{Discussion}

Despite the importance of gynaecological health screening for women with a physical disability and the acknowledged lower screening rates in this group (Chevarley et al., 2006; Ramirez et al., 2005; Smeltzer, 2006), there is a paucity of research investigating this, particularly from a general practice nurse perspective. This paper reports the first attempt to understand the role of Australian general practice nurses in women's health screening in this group. As such it provides some important insight to guide future health policy, clinical practice and nurse education.

The low levels of reported experience around physical disability by participants are surprising given that slightly under one in five Australians (18.5\% or 4.0 million Australians) are reported to have a disability (Australian Bureau of Statistics, 2011). Given the significant clinical experience of participants this would seem to indicate that perhaps all individuals with a disability were not recognised as having a disability. However, this finding resonates with previous literature that highlights that many health care professionals have a limited understanding of disability and the needs of those with a disability (Angus et al., 2012; Peters, 2012; Peters \& Cotton, 2015). This finding is significant as a lack of knowledge about disability, and consequently nurses' failure to recognise the needs of women with a disability, provides considerable barriers for women with a disability in accessing preventive health services such as gynaecological health screening (Angus et al., 2012; Diab \& Johnston, 2004; Peters \& Cotton, 2015). General practice nurses' understanding of the importance of addressing the specific needs of women with a disability, in relation to screening, can be the first step to fostering engagement with this group and improving screening rates.

A key finding of this study was the inconsistent recording and coding of physical disability in the electronic medical record. Difficulties in the identification of those in the practice population with a disability creates a challenge in the proactive provision of care tailored to meet their 
unique needs. Issues with coding and data quality in general practice electronic medical records have been previously identified (Ghosh, McCarthy, \& Halcomb, 2016). As electronic records systems become more embedded within clinical practice, and greater attention is placed on these data to inform service planning and funding, it is likely that gains in quality will continue. Consideration of data quality measures to facilitate rapid identification of consumers with a disability would create opportunities to ensure that these individuals were able to access recall and reminder screening (Ghosh et al., 2016).

Our study identified that relatively few participants had undertaken women's health screening for consumers with a disability in the four weeks prior to the survey. We asked participants to reflect on the preceding month in an attempt to minimise recall bias. It is not clear from our self-report data whether the participants who reported not screening women with a disability had avoided undertaking screening in women with a disability, failed to recognise the presence of disability within their patients or had just not encountered women with a disability in the specific time period. This highlights a need for additional research to explore these issues.

Our study identified that although most general practices employed strategies to enhance accessibility for disabled consumers such as ramps, disability parking, and wider doors, a small number of practices did not offer such features. This is an important finding as there is good evidence that lack of physical access can cause a major barrier to primary care services for those with a disability (Grabois, Nosek, \& Rossi, 1999; Graham \& Mann, 2008; Veltman, Stewart, Tardif, \& Branigan, 2001). General practice nurses have an important role in identifying environmental issues within the practice which impact consumer access and engagement, as well as advocating for positive change to be inclusive of diverse patient groups (Halcomb et al., 2017).

The innovative ways in which participants reported to have assisted women with a disability suggests that they could 'think outside the square' to accommodate the complex needs of women with a diverse range of disabilities. This is important given that a common narrative in the disability related literature calls for health care professionals to be mindful of the needs of 
women with a disability and to provide individualised care (Angus et al., 2012; Peters, 2012; Peters \& Cotton, 2015). Raising the awareness of general practice nurses around the needs of those with a disability is important to ensure that this innovation is diffused across the sector rather than confined to a small number of practices.

Our study showed that whilst post-registration education and training was a significant predictor of not undertaking screening of women with a disability, those participants with experience with disability were significantly more likely to have provided health screening. This finding may highlight the need for nurses to develop confidence in interacting with individuals with a disability beyond education and training. This notion is supported by Seccombe (2007) who, in their review of undergraduate nursing students' attitudes towards people with a disability, identified that combining educational activities with opportunities to interact with people with a disability provides the most effective means of fostering a positive attitude. Future professional development should combine education and interaction to optimise attitudes and thus enhance general practice nurses' awareness of considerations around disability.

\section{Limitations}

Whilst this study sought to gain a balanced sample, by recruiting nurses who provided women's health care in general, and then posing some questions specific to caring for those with a physical disability, it meant that participants self-selected to participate. Additionally, the sole use of a survey to collect data meant that there was no opportunity to probe the responses other than via the open-ended items. We also did not provide a definition of disability or women's health screening as this would have unnecessarily constrained the responses. We were reliant on the respondents' clinical judgement about these terms and their application to their practice.

\section{Conclusion}

Women with a physical disability gain the same health benefits from gynaecological health screening as other women. Challenges in identifying people with a physical disability from 
electronic medical records impaired the ability to target additional support to these individuals. Whilst some general practice nurses have demonstrated creativity and innovation in accommodating a range of needs to facilitate screening, not all participants reported including women with a disability in their screening practice. It is important for nurses to develop confidence in interacting with individuals with a disability and incorporating them in health promotion programs. The ongoing nature of this issue behoves policy makers and health managers, as well as clinicians and stakeholder groups, to actively translate the findings into practice and implement strategies to enhance awareness and promote service access for this vulnerable group. 


\section{References}

Angus, J., Seto, L., Barry, N., Cechetto, N., Chandani, S., Devaney, J., . . . Odette, F. (2012). Access to Cancer Screening for Women with Mobility Disabilities. Journal of Cancer Education, 27(1), 75-82.

Ashley, C., Halcomb, E., Brown, A., \& Peters, K. (2018). Experiences of registered nurses transitioning from employment in acute care to primary health care quantitative findings from a mixed methods study. Journal of Clinical Nursing, 27(1-2), 355-362.

Australian Bureau of Statistics. (2011). 4446.0 - Disability, Australia, 2009 Retrieved from

http://www.abs.gov.au/ausstats/abs@.nsf/lookup/4446.0main+features42009

Australian Institute of Health and Welfare. (2007). Cervical screening in Australia 2004-2005. Cancer series no. 38. Cat. no. CAN 33. Canberra, AIHW.

Australian Institute of Health and Welfare. (2008). Breastscreen Australia monitoring report 2004-2005. AlHW cat. no. CAN 37. Canberra, AIHW.

Australian Institute of Health and Welfare. (2011). Cervical screening in Australia 2008-2009. Cancer series no. 61. Cat. no. CAN 57. Canberra, AlHW.

Byrnes, P., Crawford, M., Peers, M., \& McGoldrick, C. (2007). Cervical screening in general practice-strategies for improving participation. Australian Family Physician, 36(3), 183.

Cheek, J., Price, K., Dawson, A., Mott, K., Beilby, J., \& Wilkinson, D. (2002). Consumer perceptions of nursing and nurses in general practice. Adelaide, South Australia.

Chevarley, F. M., Thierry, J. M., Gill, C. J., Ryerson, A. B., \& Nosek, M. A. (2006). Health, preventive health care, and health care access among women with 
disabilities in the 1994-1995 National Health Interview Survey, supplement on disability. Women's Health Issues, 16(6), 297-312.

Cooper, N. S., \& Yoshida, K. K. (2007). Cancer screening behaviors among canadian women living with physical disabilities. Archives of Physical Medicine \& Rehabilitation, 88(5), 597-603.

Diab, M., \& Johnston, M. (2004). Relationships between level of disability and receipt of preventive health services. Archives of Physical Medicine and Rehabilitation, 85(5), 749-757.

Drew, J. A. R., \& Short, S. E. (2010). Disability and Pap Smear Receipt Among U.S. Women, 2000 and 2005. Perspectives on Sexual \& Reproductive Health, 42(4), 258-266.

Ghosh, A., McCarthy, S., \& Halcomb, E. J. (2016). General practitioners' and primary care staff' perceptions on data quality in general practice: a qualitative study. BMC Family Practice, 17(50), http://www.biomedcentral.com/14712296/1417/1450.

Grabois, E. W., Nosek, M. A., \& Rossi, C. D. (1999). Accessibility of primary care physicians' offices for people with disabilities: An analysis of compliance with the americans with disabilities act. Archives of Family Medicine, 8(1), 44.

Graham, C. L., \& Mann, J. R. (2008). Accessibility of primary care physician practice sites in South Carolina for people with disabilities. Disability and Health Journal, 1(4), 209-214.

Hagglund, K. J., Clark, M. J., Hilton, S. A., \& Hewett, J. E. (2005). Access to healthcare services among persons with osteoarthritis and rheumatoid arthritis. American Journal of Physical Medicine \& Rehabilitation, 84(9), 702-711.

Halcomb, E. J., Caldwell, B., Davidson, P. M., \& Salamonson, Y. (2011). Development and psychometric validation of the General Practice Nurse Satisfaction Scale. Journal of Nursing Scholarship, 43(3), 318-327. 
Halcomb, E. J., Davidson, P., Daly, J., Yallop, J., \& Tofler, G. (2004). Australian nurses in general practice based heart failure management: Implications for innovative collaborative practice. European Journal of Cardiovascular Nursing, 3(2), 135147.

Halcomb, E. J., Davidson, P., Daly, J., Yallop, J., \& Tofler, G. (2005). Nursing in Australian general practice: Directions and perspectives. Australian Health Review, 29(2), 156-166.

Halcomb, E. J., Davidson, P. M., Salamonson, Y., \& Ollerton, R. (2008). Nurses in Australian general practice: Implications for chronic disease management. Journal of Clinical Nursing, 17(5A), 6-15.

Halcomb, E. J., Salamonson, Y., Davidson, P. M., Kaur, R., \& Young, S. A. M. (2014). The evolution of nursing in Australian general practice: a comparative analysis of workforce surveys ten years on. BMC Family Practice, 15(52), http://www.biomedcentral.com/1471-2296/1415/1452.

Halcomb, E. J., Stephens, M., Bryce, J., Foley, E., \& Ashley, C. (2017). The development of national professional practice standards for nurses working in Australian general practice. Journal of Advanced Nursing, 73(8), 1958-1969.

Harrington, A. L., Hirsch, M. A., Hammond, F. M., Norton, H. J., \& Bockenek, W. L. (2009). Assessment of primary care services and perceived barriers to care in persons with disabilities. American Journal of Physical Medicine \& Rehabilitation, 88(10), 852-863.

Hegney, D., Price, K., Patterson, E. A., Martin-McDonald, K., \& Rees, S. (2004). Australian consumers' expectations for expanded nursing roles in general practice. Australian Family Physician, 33(10), 845-848.

IBM Corp. (2013). IBM SPSS Statistics for Windows (Version 22.0). Armonk, NY. 
McCarthy, E. P., Ngo, L. H., Roetzheim, R. G., Chirikos, T. N., Li, D., Drews, R. E., \& Iezzoni, L. I. (2006). Disparities in breast cancer treatment and survival for women with disabilities. Annals of Internal Medicine, 145(9), 637-645.

Mills, J., Chamberlain-Salaun, J., Christie, L., Kingston, M., Gorman, E., \& Harvey, C. (2012). Australian nurses in general practice, enabling the provision of cervical screening and well women's health care services: a qualitative study. BMC nursing, 11(1), 23.

Morrison, E. H., George, V., \& Mosqueda, L. (2008). Primary care for adults with physical disabilities: Perceptions from consumer and provider focus groups. Family Medicine, 40(9), 645-651.

Mudrick, N. R., Breslin, M. L., Liang, M., \& Yee, S. (2012). Physical accessibility in primary health care settings: Results from California on-site reviews. Disability and Health Journal.

Nursing and Midwifery Board of Australia. (2016a). Registered nurse standards for practice. Melbourne.

Nursing and Midwifery Board of Australia. (2016b). Standards for Practice: Enrolled Nurses Melbourne.

Peters, K. (2010). Reasons why women choose a medical practice or a women's health care centre for routine health screening: Worker and client perspectives. Journal of Clinical Nursing, 19, 2557-2564.

Peters, K. (2012). Politics and patriarchy: Barriers to health screening for socially disadvantaged women. Advances in Contemporary Nursing, 40(1), 48-56.

Peters, K., \& Cotton, A. (2015). Barriers to breast cancer screening in Australia: Experiences of women with physical disabilities. Journal of Clinical Nursing, 24(3-4), 563-572. 
Phillips, C., Pearce, C., Dwan, K., Hall, S., Porritt, J., Yates, R., . . Sibbald, B. (2008). Charting new roles for Australian general practice nurses. Canberra, ACT.

Ramirez, A., Farmer, G. C., Grant, D., \& Papachristou, T. (2005). Disability and preventative screening: Results from the 2001 California Health Interview Survey. American Journal of Public Health, 95(11), 2057-2064.

Seccombe, J. A. (2007). Attitudes towards disability in an undergraduate nursing curriculum: A literature review. Nurse Education Today, 27(5), 459-465.

Smeltzer, S. C. (2006). Preventive health screening for breast and cervical cancer and osteoporosis in women with physical disabilities. Family and Community Health, 29(Supplement 1), 25S-43S.

Smeltzer, S. C., Sharts-Hopko, N. C., Ott, B., Zimmerman, V., \& Duffin, J. (2007). Perspectives of women with disabilities on reaching those who are hard to reach. Journal of Neuroscience Nursing, 39, 163-171.

The Royal Australian College of General Practitioners. (2009). Guidlines for preventive activities in general practice, 7th edition.

Veltman, A., Stewart, D. E., Tardif, G. S., \& Branigan, M. (2001). Perceptions of primary healthcare services among people with physical disabilities. Part 1: access issues. Medscape General Medicine, 3(2), 18.

Yankaskas, B. C., Dickens, P., Bowling, M., Jarman, M. P., Luken, K., Salisbury, K., . . . Lorenz, C. E. (2010). Barriers to adherence to screening mammography among women with disabilities. American Journal of Public Health, 100(5), 947953. 